\title{
Solitary nodule on the forearm
}

\section{Maghfour Soukaina', Soua Yosra', Abdejlil Nouha ${ }^{2}$, Zili Jameleddine ${ }^{1}$}

\author{
${ }^{1}$ Dermatology Department, Fattouma Bourguiba University Hospital, Monastir-Tunisia, ${ }^{2}$ Anatomopathology Department, \\ Fattouma Bourguiba University Hospital, Monastir-Tunisia
}

Corresponding author: Dr. Maghfour Soukaina, E-mail: soukou@outlook.fr

\begin{abstract}
Herein, we report the case of a 58-year-old male who presented himself with a single, slowly progressive, asymptomatic lesion on the right forearm persistent for the last three years. Clinical evaluation revealed a single firm reddish nodule. Histopathological findings from a complete excision revealed a lipidized dermatofibroma, which was characterized by the accumulation of numerous foamy cells dissected by distinctive hyalinized wiry collagen fibers and the presence of foamy macrophages. Lipidized dermatofibroma-a rare variant of dermatofibroma-must be considered in the differential diagnosis of fibrohistiocytic lesions.
\end{abstract}

Key words: Lipidized dermatofibroma; Touton-type giant cells; Fibrous hystiocytoma; Ankle-type

\section{INTRODUCTION}

Dermatofibroma (DF), also known as benign fibrous histiocytoma, is a soft-tissue tumor usually occurring in middle-aged adults and showing a slight female predominance. The typical dermatofibroma generally occurs as a single or multiple skin-colored to reddishbrown or dark-brown firm nodule located most commonly on the lower legs [1]. While its diagnosis poses little trouble in the presence of classical clinicopathological features, a dermatofibroma may show a wide variety of clinicopathological variants and, therefore, its diagnosis may become difficult. The lipidized dermatofibroma represents a rare variant of dermatofibroma. Herein, we report a typical case of this type of tumor.

\section{CASE REPORT}

A 58-year-old male presented himself with a single, slowly progressive, asymptomatic lesion on the right forearm persistent for the last three years. Past medical and family history was unremarkable. A clinical examination revealed a well-circumscribed erythematous nodule $15 \mathrm{~mm}$ in diameter (Fig. 1). The lesion, which was tender and firm on palpation, was excised under local anesthesia. Histological evaluation revealed mild epidermal acanthosis and basal pigmentation. The dermis showed a cellular proliferation of foam cells and histiocytes surrounded by hyalinized collagen bundles. Touton giant cells were also observed in some parts of the tumor (Fig. 2). These histopathologic findings led to the diagnosis of lipidized fibrous histiocytoma-one of the rare subtypes of DF.

\section{DISCUSSION}

Dermatofibroma (DF) is one of the most common types of cutaneous soft-tissue lesions [1]. The typical dermatofibroma generally occurs as a single or multiple firm reddish-brown nodule. It usually occurs on the lower extremities of young to middle-aged females [1]. Apart from its classical features, different variants have been described. Lipidized fibrous histiocytoma is a rare variant of dermatofibroma that represents approximately $2.1 \%$ of all dermatofibromas [2]. Lipidized DF was described by Iwata as ankle-type fibrous histiocytoma (dermatofibroma) due to its characteristic location on the ankles [3]. Subsequent evaluation by Wagamon demonstrated no significant difference in location between lipidized and nonlipidized dermatofibromas.

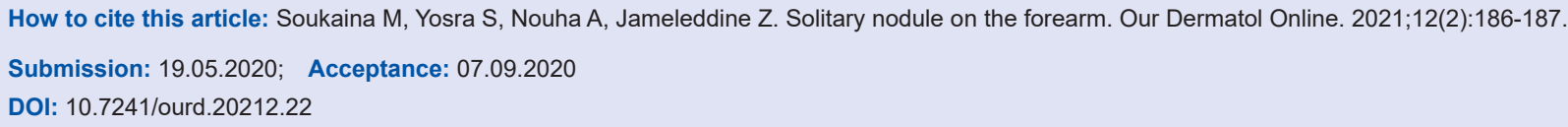




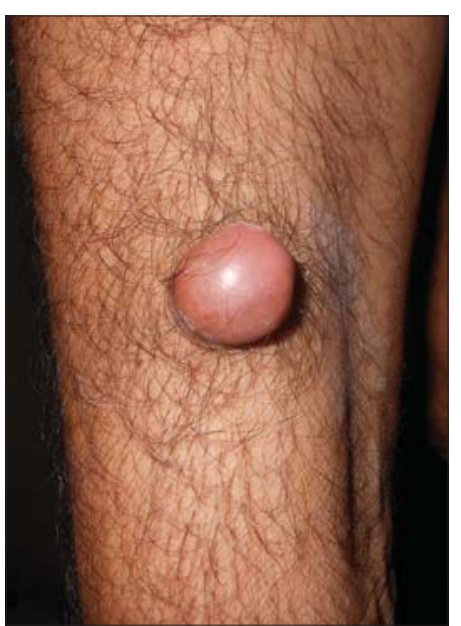

Figure 1: A solitary nodule on the forearm.

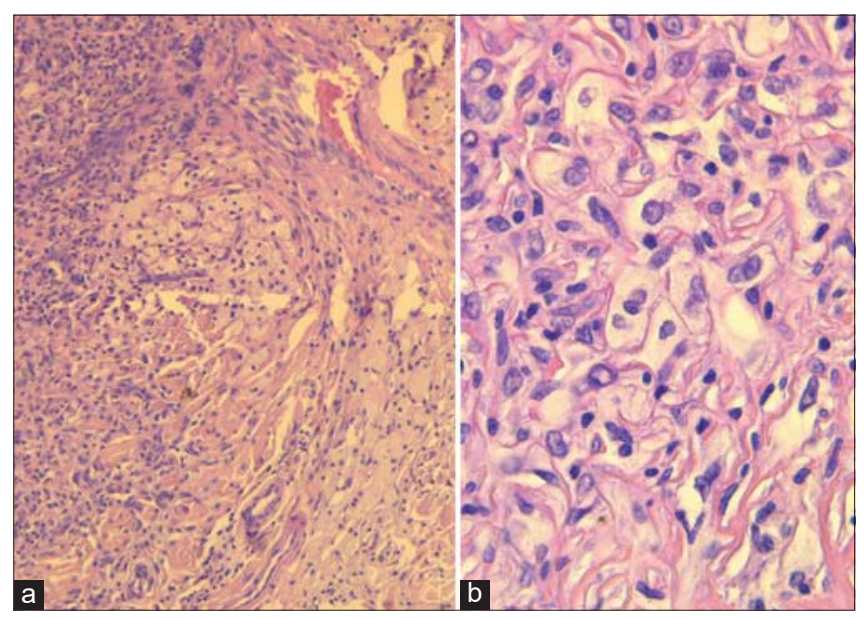

Figure 2: (a) Lipidized fibrous histiocytoma characterized by the predominance of xanthoma cells (H\&E, 40x). (b) A hyper-power view of the foamy histiocytes (H\&E, 100x).

Compared to ordinary dermatofibromas, patients with lipidized dermatofibromas tend to be older, most commonly in the fifth and sixth decades of life, and predominantly male [3]. Clinically, it manifests itself as a solitary exophytic yellow nodule usually larger than the common variant $[1,3,4]$. Apparently, it is not associated with hyperlipidemia [4]. It is frequently confused with other nodular tumors such as dermatofibrosarcoma protuberans, epidermoid carcinoma, sarcoma, and cutaneous leiomyoma [5].

Lipidized fibrous histiocytoma is defined by histological features. Its lesions are histologically characterized by the accumulation of numerous foamy cells dissected by distinctive hyalinized wiry collagen fibers. Foamy cells can be round, polygonal, or stellate in shape. These characteristic features in combination with the typical features of common dermatofibromas fulfill the criteria for the diagnosis of a lipidized dermatofibroma $[3,4]$. Touton giant cells are also frequently present [4]. The differential diagnosis includes eruptive xanthoma, granular cell tumors, tuberous xanthoma, and xanthogranuloma, but the presence of unique features such as distinctive stromal hyalinization are clues to the correct diagnosis of lipidized dermatofibroma [3].

\section{CONCLUSION}

Lipidized dermatofibroma is a rare histological variant of dermatofibroma that should be distinguished from other cutaneous foamy histiocytic lesions, which may impact patient management.

\section{Consent}

The examination of the patient was conducted according to the Declaration of Helsinki principles.

The authors certify that they have obtained all appropriate patient consent forms. In the form the patient(s) has/have given his/her/ their consent for his/her/their images and other clinical information to be reported in the journal. The patients understand that their names and initials will not be published and due efforts will be made to conceal their identity, but anonymity cannot be guaranteed.

\section{REFERENCES}

1. Calonje E. Soft tissue tumours and tumour-like conditions. In: Burns T, Breathnach S, Cox N, Griffiths C, editors. Rook's Textbook of Dermatology. 8th ed. West Sussex UK: Wiley Blackwell Ltd; 2010. pp. 56.16-18. In 2010.

2. Alves JVP, Matos DM, Barreiros HF, Bártolo EAFLF. Variants of dermatofibroma--a histopathological study. An Bras Dermatol. 2014;89:472-7.

3. Iwata J, Fletcher CD. Lipidized fibrous histiocytoma: clinicopathologic analysis of 22 cases. Am J Dermatopathol. 2000;22:126-34.

4. Luzar B, Calonje E. Cutaneous fibrohistiocytic tumours - an update. Histopathology. 2010;56:148-65. 5.

5. Srinivasan S. Enigmatic nodules on skin - a case report. Our Dermatol Online. 2012;3:206-9.

Copyright by Maghfour Soukaina, et al. This is an open-access article distributed under the terms of the Creative Commons Attribution License, which permits unrestricted use, distribution, and reproduction in any medium, provided the original author and source are credited.

Source of Support: Nil, Conflict of Interest: None declared. 